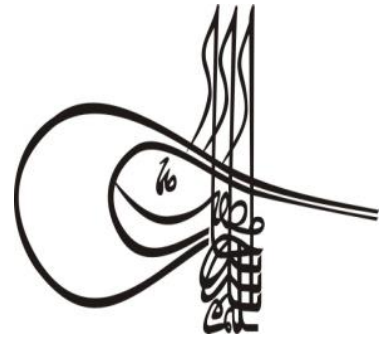

Received/Geliş: 14.01.2019

\section{Turkigh Studies Educational Sciences}

Volume 14 Issue 3, 2019, p. 949-962

DOI: 10.29228/TurkishStudies.22662

ISSN: 2667-5609

Skopje/MACEDONIA-Ankara/TURKEY

Research Article / Araştırma Makalesi

Article Info/Makale Bilgisi

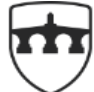

INTERNATIONAL BALKAN UNIVERSITY

EXCELLENCE FOR THE FUTUR IBU.EDU.MK

ar Report Dates/Rapor Tarihleri: Referee 1 (10.02.2019)- Referee 2 (10.02.2019)- Referee 3 (14.03.2019)

This article was checked by iThenticate.

\title{
DİJİTAL HİKAYE ANLATIMI VE 2018 TÜRKÇE DERSİ ÖĞRETIM PROGRAMININ KARŞILAŞTIRILMASI ${ }^{*}$
}

\author{
Dilara YILMAZ** - Hakan TURAN ${ }^{* * *}$
}

\begin{abstract}
ÖZ
Bu çalışmada dijital hikaye anlatımı ile 2018 Türkçe dersi öğretim programında (TDÖP) yer alan temel beceri alanlarına ait kazanımlarının karşılaştırılması amaçlanmıştır. Böylelikle çalışmanın dijital hikaye ve program kazanımları arasındaki benzerliklerin ortaya konulması bakımından alan yazına katkı sağlaması umulmaktadır. Araştırma durum çalışmasına uygun olarak düzenlenmiştir. Araştırmada veri toplama aracı olarak nitel araştırma türlerinden doküman inceleme yöntemi; verilerin analizinde ise içerik analiz tekniği kullanılmıştır. Çalışmanın örneklemi amaçlı örnekleme türlerinden ölçüt örnekleme türüne uygundur. Araştırmada ilk olarak Türkçe dersinde kazandırılması hedeflenen okuma, yazma, dinleme, konuşma ve izleme temel becerilerinden en az biri ve dijital hikayenin konu edindiği çalışmalar incelenmiştir. Aynı zamanda temel becerilerin belirtildiği Türkçe dersi öğretim programı (2, 3 ve 4 . sinıflar için) incelenmiştir. Türkçe Dersi Öğretim Programı'nda yer alan kazanımlar, dinleme, yazma, okuma ve konuşma olmak üzere dört temel dil becerisi altında gruplandırılmıştır. Buna göre programda yer alan kazanımlar ile dijital hikayenin yapısı veya özelliklerinin örtüştüğü ifadeler kodlanmıştır. Sonrasinda bu kodlar bir araya getirilmiştir. Araştırma sonucunda, Türkçe öğretim programında yer alan dinleme ve izleme, yazma, okuma ve konuşma ile ilgili birçok kazanımın dijital hikaye anlatımı ile örtüştüğü sonucuna varılmıştır. Elde edilen sonuçlara göre dijital hikaye anlatımının en çok yazma beceri alanına ait kazanımlar ile örtüştüğü görülmüştür. Bu sonuçlardan hareketle, dijital hikayenin öğrenci ve öğretmenler tarafından kullanımının arttırılması ve eğitime
\end{abstract}

\footnotetext{
* Bu çalışma Uluslararası 17. Sınıf Öğretmenliği Sempozyumunda sözlü bildiri olarak sunulmuş olup özeti basılmıştır.

** ID Arş. Gör., Kocaeli Üniversitesi, E-posta: dilara.yilmaz@kocaeli.edu.tr 
entegrasyonunun sağlanması amacıyla Türkçe Dersi Öğretim Programlarında dijital hikaye anlatımına yer verilmesi önerilebilir.

Anahtar Kelimeler: Dijital hikaye, TDÖP, dinleme, okuma, yazma ve konuşma.

\title{
COMPARISON OF DIGITAL STORYTELLING AND 2018 TURKISH CURRICULUM
}

\begin{abstract}
In this study, it is aimed to compare digital storytelling and reading, writing, speaking, listening / watching objectives in the Turkish curriculum has published in 2018. Thus, it is hoped that the study will contribute to the literature in order to reveal the similarities between the digital story and program objectives. Document analysis method was used as data collection tool in the research and content analysis technique was used in data analysis. The sample of the study is a criterion sampling from the purposeful sampling types. In the research, at least one of the basic skills aimed to be gained in Turkish lessons and the studies on the digital story and the Turkish Curriculum (for the 2nd, 3rd and 4th grades) were examined. The objectives in the Turkish Curriculum have been grouped under four basic language skills: listening, writing, reading and speaking. Accordingly, the expressions in the program and the structure or characteristics of the digital story overlap with each other. In conclusion, it is reached that digital storytelling and listening, writing, reading and speaking objectives in Turkish curriculum overlap with each other. From these $\mathrm{re}^{1}$ sults, it can be suggested that digital storytelling should be included in Turkish curriculum in order to increase the usage of digital story by students and teachers and to provide education integration.
\end{abstract}

\section{STRUCTURED ABSTRACT}

\section{Introduction}

Digital stories are one of the ways in which historical narratives, from oral narratives and cave paintings, to printed sources, have won different dimensions today under the influence of technology. With many definitions, Fokides (2016), Robin (2008) and Xu et al. (2011), digital stories are a few-minute series of stories combined with technology, media tools, and traditional story, prepared with video and music to present ideas about a particular theme. According to Yllmaz et al. (2017), the digital storytelling process begins with the writing phase and continues with the scripting of the written text and the arrangement of the images accordingly. The resulting content is digitized by the combination of multimedia media. As a final step, the prepared digital story is shared online.

As an instructional material, digital stories can be used to teach a new subject, to make it understandable, to summarize, to describe 
personal and historical events. In the educational environment, the use of digital story by the students contribute to a successful learning process by using their visual, auditory and kinesthetic skills (Abiola, 2014, K1lıç, 2014, Kurudayığlu and Bal, 2014, Robin, 2006). By creating narratives in electronic multi-media, students become more active and exciting learning activities by making sense of their own learning because they are active participants rather than passive consumers (Kocaman Karoğlu, 2015).

\section{Purpose}

The objectives in the Turkish Curriculum are grouped under four basic language skills: listening, writing, reading and speaking (MEB, 2018). In this research, it is aimed to compare digital storytelling and objectives in the Turkish Curriculum (2, 3 and 4th grade) in 2018. Due to the similarities between digital story and program objectives, it is hoped to contribute to the literature.

\section{Method}

In this researh, document review method was used from qualitative research types. In this research, among the many digital storytelling researches, 54 of them which are related to education and the Turkish Curriculum (2, 3 and 4 classes) published by Ministry of National Education in 2018 were examined. The data were analyzed by content analysis technique. Firstly, the phrases considered in the works related to the digital storytelling and thought to match the "listening /watching, writing, reading and speaking skills are listed. Then the objectives related to these skills in Turkish Curriculum are listed. Finally, overlapping objectives in the digital storytelling have been identified. Finally, the objectives which are overlapping with the digital storytelling have been identified.

\section{Results and Recommendations}

In this research, it is reached that there are similarities between the digital storytelling and the objectives of all the basic language skills involved in the Turkish lesson curriculum. The objectives in the Turkish Curriculum have been grouped under four basic language skills: listening, writing, reading and speaking. Accordingly, the expressions in the program and the structure or characteristics of the digital story overlap with each other. This findings also overlap with the other studies in literature. Kurudayığlu and Bal (2014) show that digital storytelling is effective in transferring basic language skills; Özbay and Özdemir (2014) stated that, in the case of using digital technologies effectively in reading and writing education, it is important that students play a role in promoting their socialization and their tendency to cooperate with each other in a way that they can be used effectively in reading and writing education.

As a result of comparing the objectives related to the listening / watching skills in curriculum and the studies about the digital story is discussed; Başdaş (2017) has reached a number of skillful developments in drama-based digital storytelling in the work carried out with the participation of kindergarten students, such as oral explanations, listening and completing tasks. Ciğerci (2015), has reached that in the research of the effect of digital story in the 
development of listening skills in elementary school fourth grade Turkish lesson, digital story-based listening activities developed the ability to understand what the students listened to. Ciğerci ve Gültekin (2017) reached the conclusion that using digital story improves the listening skills and motivation of the students in the research of the effect of digital story in the development of listening skills.

As a result of comparing the objectives related to the writing skills in curriculum and the studies about the digital story is discussed; Cirali Sarıca and Kaçak Usluel (2015) have reached the conclusion that digital storytelling has made a positive difference in the writing skills of students in primary school students' visual memory capacity and writing skill and the use of digital story. Yamaç (2015) stated that in the research of the effect of digital story in the writing performance of elementary school third grade students, student interaction in the classroom environment and thus the participation of the writing process in the classroom environment, where the students develop in writing quality, organization, idea, word choice, imprint and sentence fluency. Y1lmaz et al. (2017) noted that digital storytelling brings a positive change in the ability of students to read and write, in the research of the effect of digital storytelling on students' reading and writing skills.

As a result of comparing the objectives related to the reading skills in curriculum and the studies about the digital story is discussed; Bran (2010) has reached the conclusion that digital storytelling gives university students the ability to show their knowledge and skills more originally and creatively, as well as improving their literacy skills. Mokhtar et al. (2010) reported that the use of digital storytelling improves students' reading skills and vocabulary by correlating meaning and feelings with words in studying the influence of students on communication skills.

As a result of comparing the objectives related to the speaking skills in curriculum and the studies about the digital story is discussed; Michalski (2005) notes that while students create digital narratives, they also improve their writing and speaking skills because they also record their own speech at the same time, Mokhtar et al. (2011) found that students improved their vocabulary with their conversation interactions and also made progress in terms of time and place of use of words; Özer (2016) notes that digital stories that provide instruction in a technologically and fun way are effective in teaching vocabulary; Coskun (2009) stated that the use of digital story affects the speaking ability positively. In addition to these, Yüksel et al. (2011) noted that digital storytelling developed many skills, such as reading, writing, understanding, speaking, technical and social skills, language and high-level thinking skills, as a result of a survey study of digital storytelling in education worldwide. From these results, it can be suggested that digital storytelling should be included in Turkish curriculum in order to increase the usage of digital story by students and teachers and to provide education integration.

Keywords: Digital Storytelling, Turkish Curriculum, reading, writing, listening and speaking 


\section{Giriş}

Enformasyon veya bilgi çağ 1 da denilen günümüzde bilişim ve iletişim teknolojilerinin gelişmesiyle her geçen gün bilgiye erişimin kolaylaştığı söylenebilir. Teknoloji, öğrencilere bilgi ve beceri düzeylerini geliştirme ve bu sayede eğitim standartlarını da yükseltme fırsatı sağlamaktadır (Smeda vd., 2014). Eğitimde teknoloji kullanımı, konuyu somutlaştırması, öğretilmek istenen bilginin en hızlı şekilde aktarımını yapabilmesi, öğrencilerin öğrenirken eğlenmesini de sağlaması, alternatif öğrenme-öğretme yaklaşımlarını desteklemesi yönünden önemlidir (Kocaman Karoğlu, 2016; Koltuk ve Kocakaya, 2015). Teknolojinin ders ile entegrasyonu, öğrencinin konuyu anlamlı öğrenmesini ve birden fazla duyu organına hitap ederek bilginin en etkili şekilde aktarılmasının yanı sıra öğrencinin motivasyonunu, derse ilgisini ve sınıf dinamizmini desteklemektedir (Metin vd., 2013).

Deneyimlerin ve bilgilerin paylaşıldığı hikayeler, eski ve güvenilir bir öğretme aracı olup tüm kültürlerin ana unsurlarındandır. Hikaye anlatma geleneği yazılı kaynakların gün yüzüne çıkmasından çok daha eski tarihlere dayanır (İnceelli, 2005). Önceleri mağaraların duvarlarına işlenen ve daha sonra kağıtlara basılarak yaygınlaşan hikayeler günümüzde; kişisel gelişime katkı sağlayan, geleneklerin aktarılmasıyla toplumları birbirine bağlayan, çocukların ahlak ve değerler konusunda eğitilmesini sağlayan pedagojik bir araçtır (Abiola, 2014; Sylvester ve Greenidge, 2009). Aynı zamanda öğrencilerin problem çözme becerilerini, dil gelişimlerini destekleyen hayal gücü ve yaratıcılığını arttıran sosyal iletişimin önemli bir parçasıdır (Turgut ve Kışla 2015).

Tarihsel süreçte sözlü anlatımlardan ve mağara resimlerinden, basılı kaynaklara uzanan hikayelerin, teknolojinin etkisiyle günümüzde farklı boyutlar kazanan biçimlerinden birisi dijital hikayelerdir. Birçok tanımı olmakla birlikte Fokides (2016), Robin (2008) ve Xu vd. (2011)'e göre dijital hikayeler, belirli bir temayla ilgili fikir sunmak için video ve müzikle hazırlanan, teknoloji, medya araçları ve geleneksel hikayenin birleştiği birkaç dakikalık hikayeler dizisidir. Robin, (2008), Stewart ve Gachago (2016)'a göre dijital hikayeler tarihi olayları incelemek, bilgi vermek veya öğretmek için kullanılan, öğrencilerin birlikte öğrenmesine olanak tanıyan sosyal bir pedagoji ve teknoloji uygulamasıdır. Yılmaz vd., (2017)'ye göre dijital hikaye oluşturma süreci yazım aşamasıyla başlar ve yazılan metnin senaryolaştırılması ve buna uygun olarak görsellerin düzenlenmesiyle devam eder. Elde edilen içerik çoklu ortam araçlarının birleşimiyle dijitallik kazanır. Son aşama olarak ise hazırlanan dijital hikaye çevrimiçi (online) olarak paylaşılır.

Birden çok duyuya hitap eden dijital hikayeler zaman içerisinde eğitim öğretimde kullanılan bir materyal haline gelip son y1llarda popülarite kazanmıştır. Bir öğretim materyali olarak dijital hikayeler yeni bir konu ögretmek, konuyu anlaşılır hale getirmek, özetlemek, kişisel ve tarihi olayları anlatmak amacıyla kullanılabilir. Geleneksel sınıf ortamında öğrenciler hikayelerine görsellik gibi zenginlikler katabilmek için kağıt, kalem gibi araçları kullanırken, teknoloji destekli dijital hikayeler sayesinde daha etkileşimli ve zengin bir öğrenme ortamı yaratılır. Eğitim ortamında öğrencilerin dijital hikayeyi kullanması görsel, işitsel ve kinestetik yeteneklerini kullanarak başarılı bir öğrenme sürecine katkı sağlar (Abiola, 2014; Kılıç, 2014; Kurudayığlu ve Bal, 2014; Robin, 2006). Dijital hikayeler geleneksel hikayeler üzerine kurulan, interaktif bir süreçle hikayelerin birleştirilmesine firsat sağlayan, hem bilişsel hem duyuşsal öğrenmeyi destekler (Alismail, 2015; Bran, 2010; Xu vd., 2011). Öğrenciler elektronik çoklu ortamlarda anlatımlar oluşturarak pasif tüketiciler olmak yerine sürecin aktif katılımcısı oldukları için kendi öğrenmelerinden anlam çıkararak daha etkili ve heyecan verici öğrenme aktivitelerini gerçekleştirmiş olurlar (Kocaman Karoğlu, 2015; Ohler, 2005).

Türkçe Dersi Öğretim Programı'nda yer alan kazanımlar, dinleme, yazma, okuma ve konuşma olmak üzere dört temel dil becerisi altında gruplandırılmıştır (MEB, 2018, 20) Beceri alanları içerisinde dinleme, kişinin kazandığı ilk beceridir. Konuşma, okuma ve yazmanın gelişebilmesi için öncelikle dinleme becerisi geliştirilmelidir. Hem bilişsel hem devinişsel bir faaliyet olan yazma, en zor ve en son geliştirilen beceridir (Emiroğlu ve Pınar, 2013; Yılmaz vd, 2017). 
Gerekli olan dil bilincinin kazandırılması da büyük ölçüde iletişim ile olmaktadır. Türkçe Dersi Öğretim Programı'nın uygulanması sürecinde her sınıf düzeyinde işlenmesi gereken temalardan biri de iletişimdir. Bu sebeple Türkçe dersi öğretim programı, yardımlaşma temeline dayandırılmış öğretim süreci içerisinde iş birliğine dayalı öğrenme, bireysel ve sosyal gelişime katkı sağlayan ve etkili iletişim felsefesini temel alır (MEB, 2018, s. 8). ve Öztürk ve Ayvaz Tunç (2017), Papadimitriou vd. (2013), Sevilla Pavon (2015) ve Yamaç (2015)'a göre dijital hikayeler, öğrencilerin iletişim, iş birliği ve sosyalleşme becerilerine katkı sağlamakta ve öğrencinin sürece katılımını artırmaktadır.

Derse yönelik motivasyonu sağlanmış öğrencinin başarılı olması beklenmektedir. Türkçe dersi programında da, öğrenci motivasyonu artırılarak öğrencilerin akademik başarıya ulaşmaları hedeflenmektedir (MEB, 2018, s. 8). (Robin, 2008), Sylvester ve Greenidge (2009), Demirer (2013), Kahraman (2013), Kaya (2014), Kocaman Karoğlu (2014), Sever (2014), Alismail (2015), Fokides (2016) ve Niemi ve Multisilta (2016) 'e göre dijital hikayelerin farklı düzeylerde ve farklı derslerde ögrencilerin akademik başarılarını ve motivasyonlarını artırmaktadır.

Programda belirtilen dijital yetkinlik kavramı, ders sürecinde öğrenciye kazandırılması beklenen dijital okuryazarlık becerisine işaret etmektedir. Öğretim sürecine yönelik ders materyallerinde dijital okuryazarlığın yanı sıra teknoloji okuryazarlığı ve yaratıcı okuma gibi temalara yer verilmesi beklenmektedir (MEB, 2018). Robin (2008), Bran (2010), Demirer (2013), Kocaman Karoğlu (2014), Alismail (2015), Ohler (2015), Turgut (2015), Başdaş (2017)'a göre dijital hikayeler; teknoloji kullanım becerisini, yaratıcılığı, dijital okur yazarlığ 1 geliştirmektedir. Bu bilgilerden de anlaşılabileceği üzere dijital hikaye anlatımıyla Türkçe öğretim programında yer alan ifadelerin benzerlikler gösterdiği söylenebilir.

Dijital hikaye anlatımı ile Türkçe Öğretim Programını birlikte inceleyen alan yazın tarandığında ulaşılabilen çalışmaların, anadil öğretiminde dijital hikaye kullanımının tanıtılması (Kurudayığlu ve Bal, 2014) ve dijital okuryazarlıkla ilgili beceri tanımları oluşturularak, Türkçe öğretim programına uygun amaç ve kazanım önerilmesi (Özbay ve Özdemir, 2014) amacıyla yapıldığı söylenebilir. Bu çalışmada ise, dijital hikaye anlatımı ile 2018 TDÖP (2, 3 ve 4)'de yer alan okuma, yazma, konuşma, dinleme/izleme kazanımlarının karşılaştırılması amaçlanmıştır. Böylelikle çalışmanın dijital hikaye ve program kazanımları arasındaki benzerliklerin ortaya konulması bakımından alan yazına katkı sağlaması umulmaktadır. Araştırma amacı doğrulusunda aşağıdaki sorulara yanıt aranmıştır:

Dijital hikaye anlatımı,

1. Dinleme ve izleme ile ilgili kazanımlarla,

2. Yazma ile ilgili kazanımlarla,

3. Okuma ile ilgili kazanımlarla,

4. Konuşma ile ilgili kazanımlarla örtüşmekte midir?

\section{Yöntem}

\section{Araştırma Deseni}

Araştırmada dijital hikaye anlatımı ile Türkçe Dersi Öğretim Programındaki kazanımların karşılaştırılması amaçlandığından tarama modeli kullanılmıştır. Karasar (2002)'a göre tarama modelleri, geçmişte ya da halen var olan bir durumu var olduğu şekliyle betimlemeyi amaçlayan araştırma yaklaşımlarıdır.

\section{Verilerin Toplanması}

Araştırmada veriler doküman inceleme yöntemiyle elde edilmiştir. Doküman analizi, araştırılması hedeflenen olgu veya olgular hakkında bilgi içeren yazılı materyallerin analizini kapsar (Yıldırım ve Şimşek, 2013). Verilerin toplanmasında ilk aşamada dokümanlara ulaşılmaya 
çalışı1mıştır. MEB (2018) tarafından yayımlanan Türkçe dersi öğretim programı (2, 3 ve 4 . sınıflar) ve dijital hikaye anlatımının konu edildiği çalışmalar arasından Türkçe dersi kazanımlarından (dinleme/izleme, yazma, okuma ve konuşma) en az birisini içeren 54 araştırma belirlenmiş olup diğer ders ya da konular ile ilgili çalışmalar araştırmada veri olarak kullanılmamıştır. İlgili araştırmalara dijital hikaye, Türkçe dersi, okuma, yazma, dinleme, konuşma gibi anahtar kelimeler girilerek "Google scholar" arama motoru aracılığıyla ulaşılmıştır.

\section{Verilerin Analizi}

Verilerin analizinde "içerik analiz tekniği”" kullanılmıştır. İçerik analizi belli kurallara dayalı kodlar yardımıyla elde edilen verilerin sistematik olarak kategorileştirildiği, özetlendiği bir teknik olarak tanımlanır (Büyüköztürk vd., 2016).

Öncelikle dijital hikaye ile ilgili çalışmalarda geçen ve programdaki becerilerle ile örtüştüğü düşünülen ifadeler belirlenip, daha sonra bu ifadelerden hangilerinin programdaki kazanımlarla örtüştügü belirlenmiştir. Bu aşamada ilgili alan uzmanlarının görüşlerine başvurulmuştur.

\section{Bulgular}

Araştırma bulguları alt problemlere göre aşağıda verilmiştir.

\section{Birinci Alt Probleme İlişkin Bulgular}

Araştırmanın birinci alt probleminde, "Dijital hikaye anlatımı, dinleme ve izleme ile ilgili kazanımlarla örtüşmekte midir?” sorusuna yanıt aranmıştır. Türkçe öğretim programında yer alan ve dijital hikaye ile örtüştüğü düşünülen kazanımlarla dijital hikayeye ilişkin araştırma sonuçları Tablo 1'de verilmiştir*.

Tablo 1: Programdaki Dinleme/İzleme Kazanımları ve Dijital Hikaye Özellikleri

Kazanımlar Dijital Hikaye

1. Görsellerden hareketle dinleyeceği/izleyeceği metnin konusunu tahmin eder.

声 2. Dinlediklerinde/izlediklerinde geçen olayların gelişimi ve sonucu hakkında tahminde bulunur.

i 3. Dinlediği/izlediği metni anlatır

4. Dinlediklerinin/izlediklerinin konusunu belirler.

5. Dinlediklerine/izlediklerine yönelik sorulara cevap verir.

6. Sözlü yönergeleri uygular.

7. Dinleme stratejilerini uygular.

8. Konuşmacının sözlü olmayan mesajlarını kavrar.

岁 9. Dinlediklerinin/izlediklerinin ana fikrini/ana duygusunu belirler.

10. Dinlediği/izlediği hikâye edici metinleri canlandırır.

m 11. Dinledikleriyle/izledikleriyle ilgili görüşlerini ifade eder.

Başdaş (2017)'a göre drama temelli dijital hikaye anlatımı, ögrencilerin sözel açıklama, dinleme vd. becerilerini geliştirmektedir.

Ciğerci (2015)'e göre dijital hikaye destekli dinleme etkinlikleri öğrencilerin dinlediğini anlama becerilerini geliştirmektedir.

Ciğerci ve Gültekin (2017)'e göre dijital hikaye kullanımı ilkokul öğrencilerinin dinleme becerilerinin geliştirmektedir.

12. Dinlediklerinin/izlediklerinin içeriğini değerlendirir.

* Öğretim programı sarmal yapıda olduğundan, farklı sınıf düzeylerinde yer alan benzer kazanımlar tabloda tekrarlanmamıştır

Tablo 1'e göre Türkçe öğretim programında yer alan dinleme/izleme kazanımlarının Ciğerci (2015), Başdaş (2017), Ciğerci ve Gültekin (2017) tarafından yapılan araştırma sonuçlarıyla örtüştüğü söylenebilir. 


\section{2. İkinci Alt Probleme İlişkin Bulgular}

Araştırmanın ikinci alt probleminde, "Dijital hikaye anlatımı, yazma ile ilgili kazanımlarla örtüşmekte midir?" sorusuna yanıt aranmıştır. Türkçe öğretim programında yer alan ve dijital hikaye ile örtüştüğ̈̈ düşünülen kazanımlarla dijital hikayeye ilişkin araştırma sonuçları Tablo 2'de verilmiştir*

Tablo 2: Programdaki Yazma Kazanımları ve Dijital Hikaye Özellikleri Kazanımlar Dijital Hikaye

1. Anlamlı ve kurallı cümleler yazar.

2. Yazılarını görsel unsurlarla destekler.

章 3. Büyük harf ve noktalama işaretlerini uygun yerlerde Çıralı Sarıca ve Kaçak Usluel

i kullanır.

4. Yazdıklarını düzenler.

5. Yazma stratejilerini uygular.

(2015)'e göre dijital hikaye kullanımı öğrencilerin yazma becerilerinde olumlu anlamda fark yaratmaktadır.

Yamaç (2015)'a göre dijital hikaye ögrencilerin yazma niteliği, kelime seçimi, imla ve tümce akıcıllı̆ıııı desteklemektedir.

Y1lmaz vd. (2017)'ye göre dijital hikaye anlatımı sayesinde öğrencilerin okuma ve yazma becerilerinde anlamlı ve olumlu bir değişim olmaktadır.

* Öğretim programı sarmal yapıda olduğundan, farklı sınıf düzeylerinde yer alan benzer kazanımlar tabloda

Tablo 2'ye göre Türkçe öğretim programında yer alan yazma kazanımlarının Çıralı vd (2015), Yamaç (2015) ve Yılmaz (2017) tarafindan yapılan araştırma sonuçlarıyla örtüştügü söylenebilir.

\section{3. Üçüncü Alt Probleme İlişsin Bulgular}

Araştırmanın üçüncü alt probleminde, "Dijital hikaye anlatımı, okuma ile ilgili kazanımlarla örtüşmekte midir?" sorusuna yanıt aranmıştır. Türkçe öğretim programında yer alan ve dijital hikaye ile örtüştügü düşünülen kazanımlarla dijital hikayeye ilişkin araştırma sonuçları Tablo 3’te verilmiştir*. 
Tablo 3: Programdaki Okuma Kazanımları ve Dijital Hikaye Özellikleri Kazanımlar Dijital Hikaye

1. Okuma materyallerindeki temel bölümleri tanır.

2. Noktalama işaretlerine dikkat ederek okur.

4 3. Vurgu, tonlama ve telaffuza dikkat ederek okur.

\# 4. Okuma stratejilerini uygular.

i 5. Görsellerle ilgili soruları cevaplar.

6. Okuduğu metindeki hikâye unsurlarını belirler.

7. Yazılı yönergeleri kavrar.

8. Şekil, sembol ve işaretlerin anlamlarını kavrar.

9. Görsellerden hareketle okuyacağ 1 metnin konusunu tahmin eder.

क 10. Okudukları ile ilgili çıarımlar yapar.

i 11. Metinleri oluşturan ögeleri tanır.

12. Görsellerle okuduğu metnin içeriğini ilişkilendirir.

13. Metin türlerini ayırt eder.

14. Kısa ve basit dijital metinlerdeki mesajı kavrar.

13. Metinleri türün özelliklerine uygun biçimde okur. 14.Okuduğu metindeki kahramanların özelliklerini

Bran (2010)'a göre dijital hikaye öğrencilerin yazma ve becerisine katkıda bulunmasının yanı sıra onların bilgi, beceri ve yaratıcılıklarını göstermeleri için özgün bir yol sağladığını belirtmiştir.

Mokhtar vd.( 2010)'a göre dijital hikaye anlatımının okuma becerilerini olumlu yönde etkilemektedir.

岂 karşılaştırır.

ڤ 15 . Medya metinlerini değerlendirir.

$\ngtr$ 16. Bilgi kaynaklarını etkili bir şekilde kullanır.

17. Bilgi kaynaklarının güvenilirliğini sorgular.

18. Okuduğu metindeki olaylara ilişsin düşüncelerini ifade eder. tekrarlanmamıştır.

Tablo 3'e göre Türkçe öğretim programında yer alan dinleme/izleme kazanımlarının Bran (2010) ve Mokhtar vd.( 2010) tarafından yapılan araştırma sonuçlarıyla örtüştüğü söylenebilir.

\section{Dördüncü Alt Probleme İlişsin Bulgular}

Araştırmanın dördüncü alt probleminde, "Dijital hikaye anlatımı, konuşma ile ilgili kazanımlarla örtüşmekte midir?" sorusuna yanıt aranmıştır. Türkçe öğretim programında yer alan ve dijital hikaye ile örtüştüğü düşünülen kazanımlarla dijital hikayeye ilişkin araştırma sonuçları Tablo 4'te verilmiştir* 
Tablo 4: Programdaki Konuşma Kazanımları ve Dijital Hikaye Özellikleri Kazanimlar Dijital Hikaye

Michalski (2005)'e göre öğrenciler dijital hikayeler oluştururken aynı zamanda kendi konuşmalarını

1. Kelimeleri anlamlarına uygun kullanır. kaydettikleri için hem yazma hem konuşma becerilerini 2. Hazırlıksız konuşmalar yapar.

i 3. Çerçevesi belirli bir konu hakkında konuşur.

4. Konuşma stratejilerini uygular.

ilerletmiş olmaktadır.

Coşkun (2009)'a göre dijital hikaye kullanımı konuşma becerisini olumlu etkilemektedir.

\section{Sınıf içindeki tartışma ve konuşmalara katılir}

宸

6. Hazırlıklı konuşmalar yapar.
Mokhtar vd. (2011)'e göre öğrencilerin konuşma etkileşimleriyle kelime haznelerini geliştirir ve kelimelerin kullanım zamanı ve yeri konusunda da ilerleme kaydeder.

Yüksel vd. (2011)'e göre dijital hikaye kullanımı eğitimsel anlamda öğrencilerin dil becerilerini geliştirmektedir.

Özer (2016)'e göre teknolojik ve eğlenceli bir yolla öğretim sağlayan dijital hikayeler kelime öğretimi konusunda etkili ve başarılı olabilmektedir.

* Öğretim programı sarmal yapıda olduğundan, farklı sınıf düzeylerinde yer alan benzer kazanımlar tabloda tekrarlanmamıştır.

Tablo 4'e göre Türkçe öğretim programında yer alan konuşma kazanımlarının Michalski (2005), Mokhtar vd. (2011), Özer (2016) ve Yüksel vd. (2011) tarafindan yapılan araştırma sonuçlarıyla örtüştüğü söylenebilir.

\section{Sonuç Tartışma ve Öneriler}

Djital hikaye anlatımı ile 2018 Türkçe Dersi Öğretim Programındaki kazanımların karşılaştırılması amacıyla yapılan bu çalıșma sonucunda, dijital hikaye anlatımı ile TDÖP'de yer verilen temel becerilerin tümüne ait kazanımlar arasında benzerlikler bulunduğu sonucuna ulaşılmıştır. $\mathrm{Bu}$ sonuçlara benzer olarak Kurudayığlu ve Bal (2014), dijital hikayenin temel dil becerilerinin aktarımında etkili olduğu; klasik ders anlatımının dışına çıkarak öğrencinin derse yönelik tutum ve davranışlarını iyileştirebilmesi sebebiyle anadil öğretiminde kullanılmaya uygun olduğu, Özbay ve Özdemir (2014) ise, dijital teknolojilerin okuma ve yazma eğitiminde etkili bir biçimde kullanılması hâlinde öğrencilerin sosyalleşmesi ve iş birlikli çalışmaya olan yatkınlıklarını geliştirici bir rol oynadığını belirtmişlerdir.

Dinleme ve izleme beceri alanına ait kazanımlar ile dijital hikayenin konu edildiği çalışmalar karşılaştırıldığında; Başdaş (2017), anaokulu öğrencilerinin katılımıyla gerçekleştirilen çalışmada, drama temelli dijital hikaye anlatımının öğrencilerin sözel açıklama, dinleme ve görev tamamlama becerisi gibi birçok beceriyi geliştiğini, Ciğerci (2015), ilkokul dördüncü sınıf Türkçe dersinde dinleme becerilerinin gelişiminde dijital hikayenin etkisinin incelendiği çalışmada, dijital hikaye destekli dinleme etkinliklerinin öğrencilerin dinlediğini anlama becerilerini geliştirdiğini, Ciğerci ve Gültekin (2017), Türkçe dinleme becerilerinin gelişiminde dijital hikayenin etkisinin incelendiği çalışmada, dijital hikaye kullanımının öğrencilerin dinleme becerilerini ve motivasyonlarını geliştirdiğini belirtmişlerdir.

Yazma beceri alanına ait kazanımlar ile dijital hikayenin konu edildiği çalışmalar karşılaştırıldığında; Çıralı Sarıca ve Kaçak Usluel (2015) ilkokul öğrencilerinin görsel bellek kapasitesi ve yazma becerisi ile dijital hikaye kullanımın ilişkilendirdiği çalışmada, dijital hikaye anlatımının öğrencilerin yazma becerilerinde olumlu anlamda fark yarattığını; Yamaç (2015) ilkokul üçüncü sınıf öğrencilerinin yazma performanslarında dijital hikayenin etkisini incelendiği çalışmada, öğrencilerin yazma niteliği, organizasyon, fikir, kelime seçimi, imla ve tümce akıcılığı konularında gelişme gösterdikleri, sınıf ortamında öğrenci etkileşimi ve böylelikle yazma sürecine katılımının 
arttı̆̆ını; Yılmaz vd. (2017) dijital hikaye anlatımının öğrencilerin okuma ve yazma becerilerine etkisinin incelendiği çalışmada, dijital hikaye anlatımının öğrencilerin okuma ve yazma becerilerinde olumlu değişim meydana getirdiğini belirtmişlerdir.

Okuma beceri alanına ait kazanımlar ile dijital hikayenin konu edildiği çalışmalar karşılaştırıldığında; Bran (2010) dijital hikayenin, üniversite öğrencilerine kendi bilgi ve becerilerini daha özgün ve yaratıcı şekilde gösterebilme yetisi kazandırdığı, ayrıca öğrencilerin okuma yazma becerilerini geliştirdiğini, Mokhtar vd. (2010), dijital hikaye kullanımının öğrencilerin iletişim becerilerine etkisini incelediği çalışmada, dijital hikayenin anlam ve duyguları sözlerle ilişkilendirebilmesiyle öğrencilerin okuma becerileri ve kelime haznesini geliştirdiğini belirtmişlerdir.

Konuşma beceri alanına ait kazanımlar ile dijital hikayenin konu edildiği çalışmalar karşılaştırıldığında; Michalski (2005), öğrencilerin dijital hikayeler oluştururken aynı zamanda kendi konuşmalarını kaydettikleri için hem yazma hem konuşma becerilerini ilerlettiğini, Mokhtar vd. (2011), öğrencilerin konuşma etkileşimleriyle kelime haznelerini geliştirip kelimelerin kullanım zamanı ve yeri konusunda da ilerleme kaydettiğini; Özer (2016), teknolojik ve eğlenceli bir yolla öğretim sağlayan dijital hikayelerin kelime öğretimi konusunda etkili olduğunu; Coşkun (2009), dijital hikaye kullanımının konuşma becerisini olumlu etkilediğini belirtmişlerdir. Bunlara ek olarak Yüksel vd. (2011) dijital hikaye anlatımının dünya genelinde eğitimde kullanımına ilişkin uyguladığı anket çalışmasının sonucunda dijital hikayenin, okuma, yazma, anlama, konuşma, teknik ve sosyal beceriler, dil ve üst düzey düşünme becerileri gibi birçok beceriyi geliştirdiğini belirtmişlerdir.

Sonuç olarak, Türkçe ögretim programında yer alan dinleme ve izleme, yazma, okuma ve konuşma ile ilgili birçok kazanımın dijital hikaye anlatımı ile örtüştüğü söylenebilir. Bu sonuçlardan hareketle, dijital hikayenin öğrenci ve öğretmenler tarafından kullanımının arttırılması ve eğitime entegrasyonunun sağlanması amacıyla;

- $\quad$ Türkçe Dersi Öğretim Programlarında dijital hikaye anlatımına yer verilmesi,

- Dijital hikayelerin okul dışı ortamlarda da kullanılması,

- $\quad$ Dil öğretiminde dijital hikaye anlatımına da yer verilmesi,

- $\quad$ Öğretmenlere dijital hikaye anlatımına yönelik hizmet içi eğitim verilmesi önerilebilir.

\section{KAYNAKÇA}

Abiola, L. L. (2014). The effect of digital storytelling on kindergarten pupils' achievement in moral instruction in basic schools in Oyo State. IOSR Journal of Research \& Method in Education (IOSR-JRME, 4(5). 26-34.

Alismail, H. A. (2015). Integrate digital storytelling in education. Journal of Education and Practice, 6(9), 126-129.

Başdaş, F. ( 2017). Drama temelli dijital hikaye anlatıcıllğının altı yaş çocuklarının bazı sosyal becerilerinin gelişimine etkisi (Yayımlanmamış Yüksek Lisans Tezi). Adnan Menderes Üniversitesi Sosyal Bilimler Enstitüsü, Aydın.

Bran, R. (2010). Message in a bottle telling stories in a digital world. Procedia Social and Behavioral Sciences, (2), 1790-1793. doi:10.1016/j.sbspro.2010.03.986 Büyüköztürk, ş., Kılıç Çakmak, E., Akgün, Ö. E., Karadeniz, ş. \& Demirel, F. (2016) Bilimsel araştırma yöntemleri. Ankara: Pegem Akademi.

Ciğerci, F. M., Gültekin, M. (2017). Use of digital stories to develop listening comprehension skills. Issues in Educational Research, 27(2),252-268 
Ciğerci, F. M. (2015). İlkokul dördüncü sınıf türkçe dersinde dinleme becerilerinin geliştirilmesinde dijital hikâyelerin kullanılması (Yayımlanmamış Doktora Tezi). Anadolu Üniversitesi Eğitim Bilimleri Enstitüsü, Eskişehir.

Coşkun, M. (2009). Ana dili eğitiminde parçalarüstü birimlerin önemi ve teknoloji destekli olarak kavratılmas1. Bilig/Türk Dünyast Sosyal Bilimler Dergisi, (48), 41-52.

Çıralı Sarıca, H., Kaçak Usluel, Y. (2015). The effect of digital storytelling on visual memory and writing skills. Computers \& Education, (94), 298-309.

Davis, A., McGrail, E. (2013). Proof-Revising with podcasting: keeping readers in mind as students listen to and rethink their writing. The Reading Teacher, 62(6), 522-529.

Demirer, V. (2013). Illköğretimde e-öyküleme kullanımları ve örnekleri (Yayımlanmamış Doktora Tezi). Necmeddin Erbakan Üniversitesi Eğitim Bilimleri Enstitüsü, Konya.

Dogan,B. (2007). Implementation of digital storytelling in the classroom by teachers trained in a digital storytelling workshop (Yayımlanmamış Doktora Tezi). University of Houston Faculty of the College of Education, Houston.

Emiroğlu, S., Pınar, F. N. (2013). Dinleme becerisinin diğer beceri alanları ile ilişkisi. Turkish Studies, $8(4), 769-782$.

Fokides, E. 2016. Using digital storytelling to help first-grade students' adjustment to school. Contemporary Educational Technology, 7(3), 190-205.

Göçen, G. (2014). Dijital öyküleme yönteminin öğrencilerin akademik başarı ile öğrenme ve ders çalışma stratejilerine etkisi (Yayımlanmamış Yüksek Lisans Tezi). Muğla Sitkı Koçman Üniversitesi Eğitim Bilimleri Enstitüsü, Muğla.

Hasni Mokhtar, N., Farida Abdul Halim,M., Syed Kamarulzaman, S.Z (2010). The effectiveness of storytelling in enhancing communicative skills. Procedia Social and Behavioral Sciences, 18, $163-169$.

Kahraman, Ö. (2013). Dijital hikayecilik metoduyla hazırlanan ögretim materyallerinin ögrenme döngüsü giriş aşamasında kullanılmasının fizik dersi başarısı ve motivasyonu düzeyine etkisi (Yayımlanmamış Doktora Tezi). Balıkesir Üniversitesi Fen Bilimleri Enstitüsü, Balıkesir.

Karakoyun, F. (2014). Çevrimiçi ortamda oluşturulan dijital öyküleme etkinliklerine iliş̧kin öğretmen adaylarl ve ilköğretim ögrrencilerinin görüşlerinin incelenmesi (Yayımlanmamış Doktora Tezi). Anadolu Üniversitesi Eğitim Bilimleri Enstitüsü, Eskişehir.

Karasar, N. (2002). Bilimsel araştırma yöntemi. Ankara: Nobel Yayın Dağıtım.

Kilıç, Figen. (2014). Awareness and cognitive load levels of teacher candidates towards student products made by digital storytelling. Turkish Online Journal of Distance Education (TOJDE), 15(3), 94-107.

Kocaman Karoglu, A. (2014). Personal voices in higher education:a digital storytelling experience for preservice teachers. Education and Information Technologies, (21), 1153-1168.

Kocaman Karoğlu, A. (2015). Öğretim sürecinde hikâye anlatmanın teknolojiyle değişen doğası: dijital hikâye anlatımı. Eğitim Teknolojisi Kuram ve Uygulama Dergisi, 5(2), 89-106.

Kocaman Karoğlu, A. (2016). Okul öncesi eğitimde dijital hikâye anlatımı üzerine öğretmen görüşleri. Turkish Online Journal of Qualitative Inquiry (TOJQI), 7(1), 175-205. 
Koltuk, N., Kocakaya, S. (2015). 21.yüzy1l becerilerinin gelişiminde dijital öykülemeler: ortaöğretim öğrencilerinin görüşlerinin incelenmesi. Eğitim ve Öğretim Araştırmaları Dergisi, 4(2), 354363.

Kurudayığlu, M., Bal, M. (2014). Ana dili eğitiminde dijital hikâye anlatımlarının kullanımı. Sakarya Üniversitesi Eğitim Fakültesi Dergisi, (28), 74-95.

Lambert, J. (2010). Digital storytelling cookbook. California.

MEB. (2018). 1-8. Sınıf Türkçe Öğretim Programı. Talim Terbiye Kurulu: Ankara.

Metin, M., Birişçi, S., Coşkun, K. (2013). Öğretmen adaylarının öğretim teknolojilerine yönelik tutumlarının farklı değişkenler açısından incelenmesi. Kastamonu Eğitim Dergisi, 21 (4), $1345-1364$

Michalski, P, Hodges, D., Banister, S. (2005). Digital storytelling in the middle childhood special education classroom: a teacher's story of adaptations. Teaching Exceptional Children Plus, 1(4), 1-13.

Mokhtar, N. H., Abdul Halim, M. F., Kamarulzaman, S. Z. S. (2011). The effectiveness of storytelling in enhancing communicative skills. Procedia Social and Behavioral Sciences, (18), 163-169.

Morgan, H. (2014). Using digital story projects to help students improve in reading and writing. Reading Improvement, 51(1), 20-26.

Ohler, J. (2005). The World of digital storytelling. Educational Leadership, 63(4), 44-47.

Özbay, M., Özdemir, O. (2014). Türkçe öğretim programı için bir öneri:dijital okuryazarlığa yönelik amaç ve kazanımlar. Research in Reading \& Writing Instruction, 2 (2), 31-40.

Özer, M. (2016). Exploring the role of digital storytelling in vocabulary learning and retention: a case study at harran university (Yayımlanmamış Yüksek Lisans Tezi). Çağ Üniversitesi Sosyal Bilimler Enstitüsü, Mersin.

Öztürk, A., Ayvaz Tunç, Ö. (2017). The effect of digital storytelling project on fine arts high school students' teamwork skills. Journal Of Educational And Instructional Studies In The World, 7(4), 58-68.

Papadimitriou, E., Kapaniaris, A., Zisiadis, D., Kalogirou, E. (2013). Digital storytelling in kindergarten: an alternative tool in children's way of expression. Mediterranean Journal of Social Science, 4(11), 389-396.

Robin, B. R. (2008). Digital storytelling: a powerful technology tool for the 21 st century classroom. Theory Into Practice, (47), 220-228.

Robin, B. R. The Educational Uses of Digital Storytelling (2006).

Sever, T. (2014). An investigation into the impact of digital storytelling on the motivation level of students (Yayımlanmamış Yüksek Lisans Tezi). Çanakkale On Sekiz Mart Universitesi Eğitim Bilimleri Enstitüsü, Çanakkale.

Sevilla-Pavón, Ana.(2015). Examining collective authorship in collaborative writing tasks through digital storytelling. European Journal of Open, Distance and E-Learning, 18(1). 1-8.

Smeda, N., Dakich, E., Sharda, A. (2014). The effectiveness of digital storytelling in the classrooms: a comprehensive study. Smart Learning Environments, 1(6). 1-21.

Stewart, K., Gachago, D. (2016). Being human today: A digital storytelling pedagogy for transcontinental border crossing. British Journal of Educational Technology, 47(3), 528-542. 
Sylvester, R., Greenidge, W.(2009). Digital Storytelling: Extending the potential for struggling writers. The Reading Teacher, 63(4), 284-295.

Toki, E. I., Pange, J. (2014). ICT use in early childhood education: storytelling. TILTAI, (1), 183-192.

Turgut, G., Kışla, T. (2015a). Bilgisayar destekli hikaye anlatımı yöntemi: alanyazın araştırması. Turkish Online Journal of Qualitative Inquiry, 6(2), 97-119.

Turgut, G. (2015b). Okul öncesi eğitimi için gelişstirilen hikaye oluşturma yazılımına yönelik görüşlerin incelenmesi (Yayımlanmamıș Yüksek Lisans Tezi). Ege Üniversitesi Fen Bilimleri Enstitüsü, İzmir.

Xu, Y., Park, H., Baek, Y. (2011). New approach toward digital storytelling: an activity focused on writing selfefficacy in a virtual learning environment. Educational Technology \& Society, 14 (4), 181-191

Yamaç, A. (2015). İlkokul üçüncü sınıf ögrencilerinin yazma becerilerinin gelişiminde dijital hikayelerin etkisi (Yayımlanmamış Doktora Tezi). Gazi Üniversitesi Eğitim Bilimleri Enstitüsü, Ankara.

Yıldırım, A. ve Şimşek, H. (2016).Sosyal bilimlerde nitel araştırma yöntemleri . Ankara: Seçkin Yayınc1lık. (10. Bask1).

Yılmaz, Y., Üstündağ, M. T., Güneş, E., Çalışkan, G. (2017a). Dijital hikayeleme yöntemi ile etkili Türkçe öğretimi. Eğitim Teknolojisi Kuram ve Uygulama Dergisi, 7(2), 254-275.

Yılmaz, Y., Üstündağ, M. T., Güneş, E. (2017b). Öğretim materyali olarak dijital hikâye geliştirme aşamalarının ve araçlarının incelenmesi. Abant İzzet Baysal Üniversitesi Eğitim Fakültesi Dergisi, 17 (3), 1621-1640.

Yüksel, P., Robin, B. R., Mcneil, A. (2011). Educational Uses of Digital Storytelling Around the World 